\title{
Parametric simulation of ceiling panels exposed to aggressive environments
}

\author{
Iveta Hegedüsová ${ }^{1, *}$, and Sergej Priganc ${ }^{1}$ \\ ${ }^{1}$ Faculty of Civil Engineering, Institute of Structural Engineering, Technical University of Košice, \\ Slovakia
}

\begin{abstract}
The subject matter of the contribution is findings obtained from a parametric simulation of ceiling panels behaviour under a change of determined parameters. The optional parameters included concrete strength, reinforcement cross-section area, and concrete covering. The experiment investigated an impact of the given parameters changes onto the element resistance which was evaluated on the basis of the ultimate state of usability, namely from the point of view of crack checking and deflection measuring. Panel behaviour was presented by a load-deflection relation and crack topography
\end{abstract}

\section{Introduction}

During their service life, concrete structures, as well as any other type of structures, are exposed to various conditions and impacts of the environment. Their functionality is most often influenced by mechanical loading, impacts of the aggressive environment, humidity and increased temperatures [5]. Structures become worn-out and material corrosion occurs. Degradation of structures can be observed in all kinds of structures and construction elements, whether in horizontal or vertical elements, or properties of large or small scales. As it is known from the current practice, degradation of structures is also caused by preferring more subtle structures which are used to maximise economy and to optimise the use of construction materials.

The article is aimed at a reinforced concrete ceiling in an agricultural building consisting of lightened ceiling panels exposed to an aggressive environment for a long time. Basic problems of agricultural structures include problems of load-bearing elements. Although, during their construction, the elements were laid requirements from both technological and operational points of view, today it is obvious that load-bearing elements, made of both reinforced concrete and steel, show signs of degradation which was primarily caused by high relative humidity, gases, barn acids, bacteria and fungi [6]. The aim of the research is to evaluate conditions of the ceiling precast elements in the chosen buildings, to carry out a thorough diagnostics, and subsequently to compare the obtained data with results of the parametric analysis. The aim of the parametric analysis is to examine behaviour of a modelled beam and to find out whether it is possible to predict durability of these elements based on knowledge of their input parameters.

\footnotetext{
*Corresponding author: iveta.hegedusova@tuke.sk
} 


\section{Description of the object}

The aim of this study is to analyse and evaluate ceiling panels conditions in the real environment of the cow barns of K-174 type Fig. 1. This type of an agricultural structure is a standard representative of large capacity cow barns. The structure forms a separate closed technological operational livestock farming unit to stable 174 pieces of dairy cows [1].
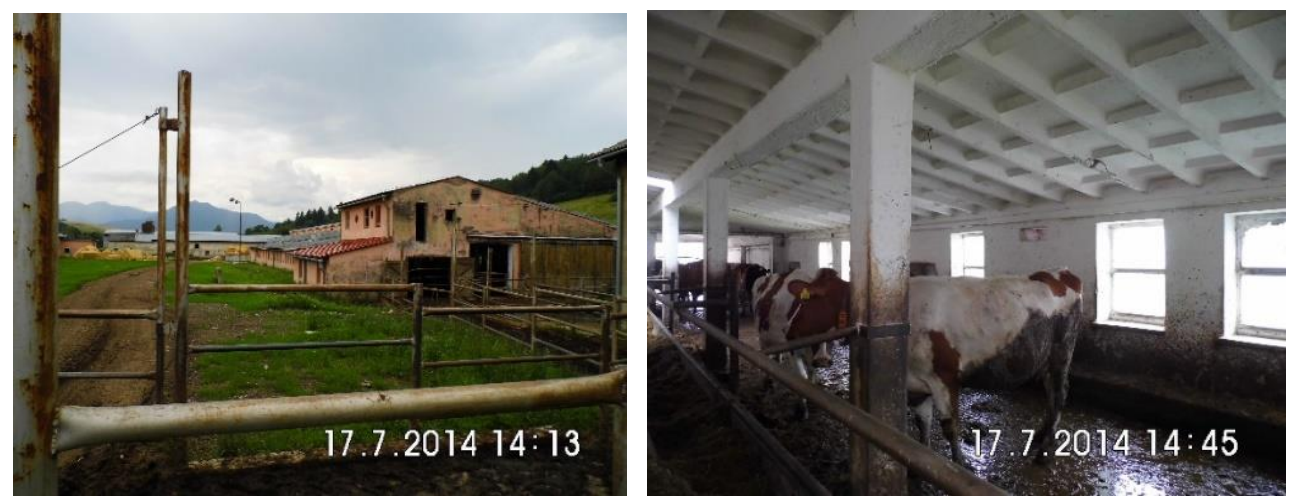

Fig. 1. Cow barns of K-174 type.

The subject matter is a general-purpose reinforced concrete prefabricated structure, combined with external load-bearing brick walls, and no loft Fig. 2. It is a single-storey transit building built as a 5-nave structure with four longitudinal prefabricated reinforced concrete frames. The system altogether comprises ten elements, assembled as single-storey structures with cantilevered columns, single beams, and single embedded ceiling panels. The roof structure gradient is $10^{\circ}$. Module axes are spaced by $4500 \mathrm{~mm}$ and $6000 \mathrm{~mm}$. The cow barn roof bearing structure consists of lightened ribbed reinforced concrete ceiling panels marked as SZD 10n - 450 Fig. 2.

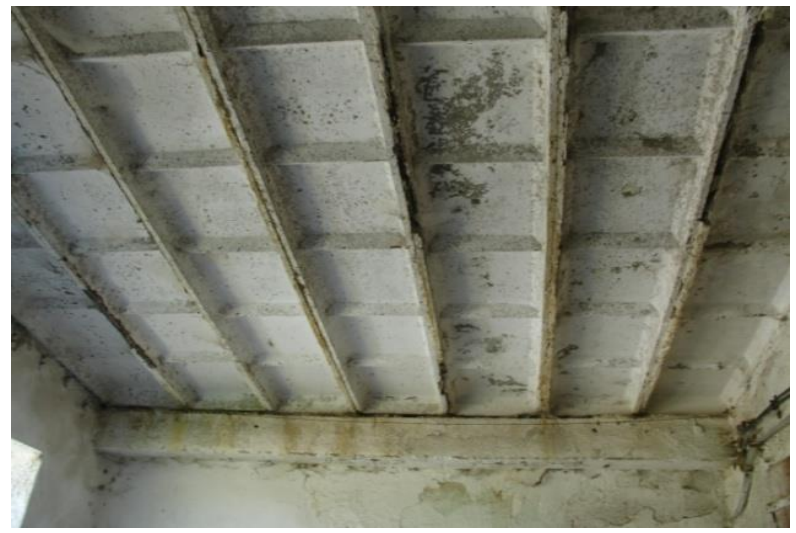

Fig. 2. Ceiling panels as SZD 10n-450.

\section{Parametric analysis}

The analysis was aimed at designing such parametric models that could be used to simulate ceiling panels behaviour while changing chosen parameters under real conditions. For the 
purpose of the parametric analysis we used ATENA V4 software [2] which is based on the finite element method.

\subsection{Model design and input parameters}

Modelling of the chosen task was carried out in a pre-processing phase during which an input file was created in GiD software environment: element geometry, material characteristics editing, grid formation, setting calculation parameters and boundary conditions. In this mode, so-called monitors, recording measured parameters, deflections and cracks, were set in specified monitored spots on the panel. Static tasks were modelled in Static software.

Loading was carried out by an increase in surface load, applied in partial values in a set number of steps. The parametric model copied real dimensions and characteristics of the ceiling panel components, though transverse panel ribs were modified which led to a significant elimination of the number of necessary elements, and thus to the grid topography simplification. Altogether, the model comprised three types of materials, namely concrete, reinforcement, and a steel board which was used as a load spreading board at panel supporting areas to avoid local concrete failures at linear supports.

A model of concrete and steel reinforcement was determined by a material offered by ATENA programme [3].

Data used in calculation included the original design strength, $25 \mathrm{MPa}$, and the strength measured in the actual structure in the K-174 building, $23 \mathrm{MPa}$ and $21 \mathrm{MPa}$. In the analysis, the original $8 \mathrm{~mm}$ diameter of the longitudinal reinforcement, a presumed decreased $7 \mathrm{~mm}$ diameter (due to reinforcement corrosion), and an added $10 \mathrm{~mm}$ diameter (due to a substitution in some of the panels) were used. Material characteristics are presented in Table 1.

Table 1. Material characteristics for parametric simulation.

\begin{tabular}{|c|c|c|c|c|}
\cline { 2 - 5 } \multicolumn{1}{c|}{} & $F_{c, \text { cube }}[\mathrm{MPa}]$ & 25 & 23 & 21 \\
\hline \multirow{4}{*}{ Concrete } & $F_{c}[\mathrm{MPa}]$ & 21 & 19 & 17 \\
\cline { 2 - 5 } & $F_{t}[\mathrm{MPa}]$ & 2.301 & 2.180 & 2.050 \\
\cline { 2 - 5 } Reinforcement & $E_{c}[\mathrm{GPa}]$ & 28.062 & 27.065 & 26.003 \\
\hline & $\phi[\mathrm{mm}]$ & 8 & 10 & 7 \\
\cline { 2 - 5 } & $F_{\text {sy }}[\mathrm{MPa}]$ & 350 & 350 & 350 \\
\cline { 2 - 5 } & $E_{y}[\mathrm{GPa}]$ & 200 & 200 & 200 \\
\cline { 2 - 5 } & $F_{\text {st }}[\mathrm{MPa}]$ & 378 & 378 & 378 \\
\hline
\end{tabular}

Legend:

$F_{c}$, cube - cube strength of concrete

$F_{c} \quad$ - cylinder strength of concrete

$F_{t} \quad$ - tensile strength of concrete

$E_{c} \quad$ - elastic modulus of concrete

$F_{s y} \quad$ - strength of reinforcement (yield strength steel)

$E_{s} \quad$ - elastic modulus of reinforcement

$F_{s t} \quad$ - tensile strength of reinforcement $-f_{s y} . k(k=1,08)$

The last variable parameter in the analysis was the concrete covering, where the original design value stated in the design documentation was $10 \mathrm{~mm}$, and values found out by actual examination were 20 and $30 \mathrm{~mm}$. For the parametric study we prepared 27 panels (beams) 
labelled as NVK (beam / reinforcement / concrete covering). The list of the panels with input parameters is shown in Table 2.

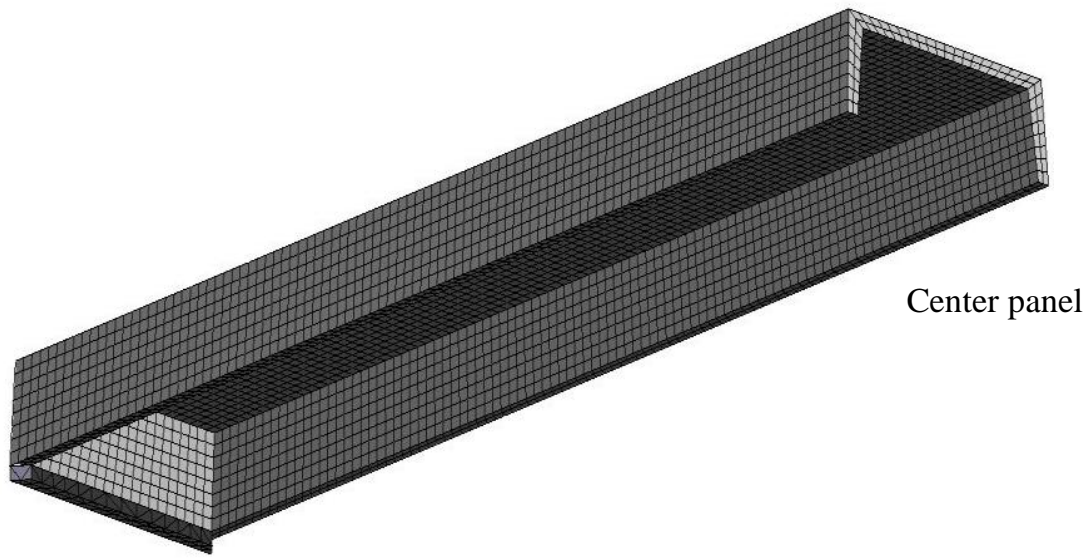

Fig. 3. Model of panel.

Table 2. Input parametes of panel.

\begin{tabular}{|c|c|c|c|}
\hline \multicolumn{4}{|c|}{ Input parametes } \\
\hline Panel labelling & $\begin{array}{c}\text { Concrete fck cube } \\
{[\mathrm{MPa}]}\end{array}$ & $\begin{array}{c}\text { Reinforcement } \\
\text { diameter } \varnothing[\mathrm{mm}]\end{array}$ & Concrete cover $[\mathrm{mm}]$ \\
\hline N1V1K1 & 25 & 8 & 10 \\
\hline N1V1K2 & 25 & 8 & 20 \\
\hline N1V1K3 & 25 & 8 & 30 \\
\hline N1V2K1 & 25 & 10 & 10 \\
\hline N1V2K2 & 25 & 10 & 20 \\
\hline N1V2K3 & 25 & 10 & 30 \\
\hline N1V3K1 & 25 & 7 & 10 \\
\hline N1V3K2 & 25 & 7 & 20 \\
\hline N1V3K3 & 25 & 7 & 30 \\
\hline $\mathrm{N} 2 \mathrm{~V} 1 \mathrm{k} 1$ & 23 & 8 & 10 \\
\hline $\mathrm{N} 2 \mathrm{~V} 1 \mathrm{~K} 2$ & 23 & 8 & 20 \\
\hline N2V1K3 & 23 & 8 & 30 \\
\hline $\mathrm{N} 2 \mathrm{~V} 2 \mathrm{~K} 1$ & 23 & 10 & 10 \\
\hline N2V2K2 & 23 & 10 & 20 \\
\hline $\mathrm{N} 2 \mathrm{~V} 2 \mathrm{~K} 3$ & 23 & 10 & 30 \\
\hline $\mathrm{N} 2 \mathrm{~V} 3 \mathrm{~K} 1$ & 23 & 7 & 10 \\
\hline N2V3K2 & 23 & 7 & 20 \\
\hline N2V3K3 & 23 & 7 & 30 \\
\hline N3V1K1 & 21 & 8 & 10 \\
\hline $\mathrm{N} 3 \mathrm{~V} 1 \mathrm{~K} 2$ & 21 & 8 & 20 \\
\hline N3V1K3 & 21 & 8 & 30 \\
\hline N3V2K1 & 21 & 10 & 10 \\
\hline $\mathrm{N} 3 \mathrm{~V} 2 \mathrm{~K} 2$ & 21 & 10 & 20 \\
\hline N3V2K3 & 21 & 10 & 30 \\
\hline N3V3K1 & 21 & 7 & 10 \\
\hline N3V3K2 & 21 & 7 & 20 \\
\hline N3V3K3 & 21 & 7 & 30 \\
\hline
\end{tabular}


Due to symmetry, it was sufficient to model only a half of the panel which decreased the calculation time. A parametric model of a panel shaped as a finite element grid is shown in Fig. 3.

The prepared input file was exported to the Atena environment where the calculation was executed. Atena software was used to process results.

\subsection{Parametric simulation}

After entering input parameters the software started a calculation whose purpose was to examine how the modelled ceiling panel would behave. Behaviour of the panel obtained from the parametric simulation is presented by a deflection-load ratio and crack topography. Fig. 4. shows a demonstration of panel deformation with recorded deflection values, while Fig. 5. presents the crack topography. A half of the panel is presented.

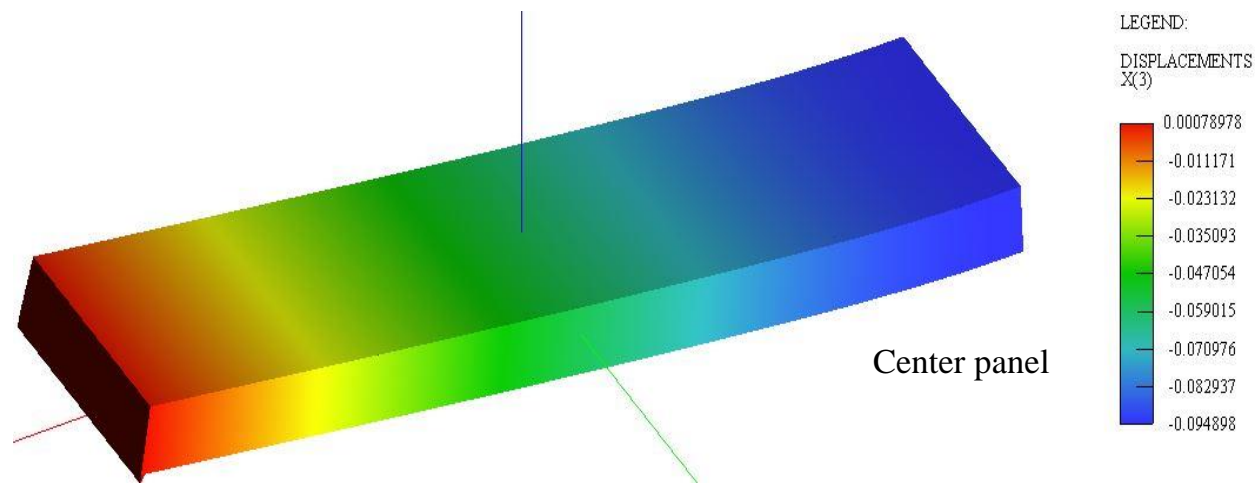

Fig. 4. Deflection panel $[\mathrm{mm}]$.

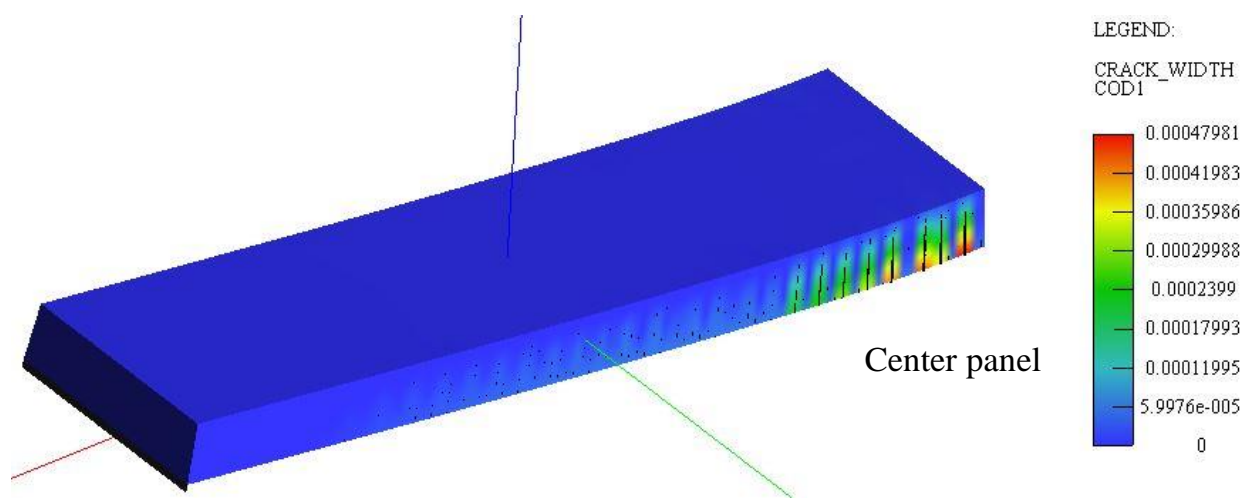

Fig. 5. The bending cracks panel $[\mathrm{mm}]$.

For the modelled ceiling panels values of deflection in the span middle, dependent on the given load, were obtained by calculation. The results were subsequently processed in graphs Fig. 6. A graph showing a deflection-load ratio for panel N1V1K1 is presented as an example. Afterwards, load values at which a crack width reached limit values in accordance with standard [4] were calculated. Also, load values at which panel deflection reached a limit value in accordance with [4] were calculated. Values for panel N1V1K1 are presented as an example. 


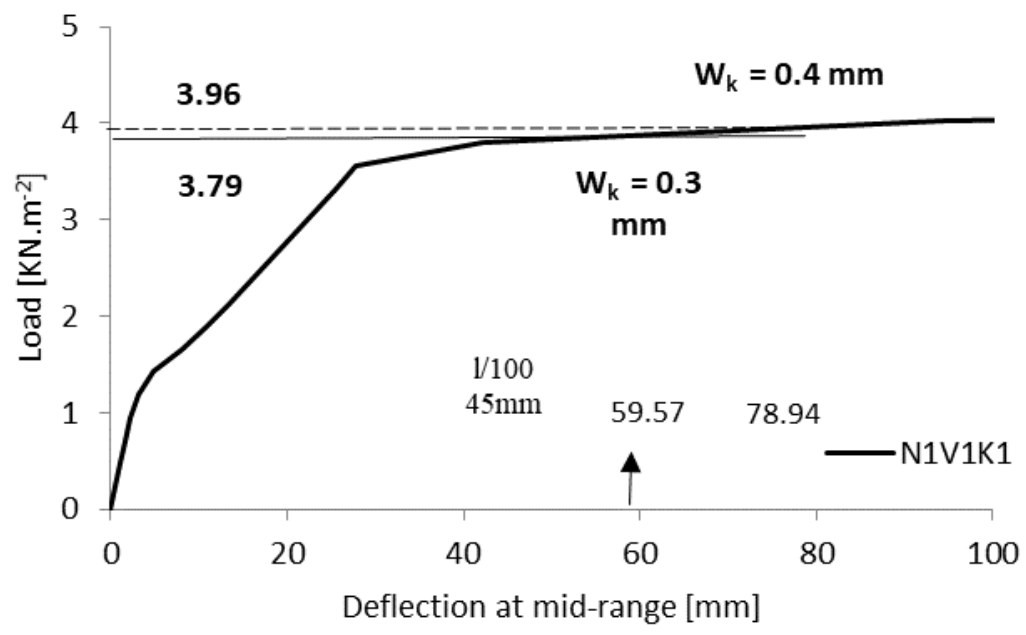

Fig. 6. Stress strain diagram - panel N1V1K1.

\section{Parametric analysis results}

The parametric study pointed out possible ceiling panels behaviour from a possible change of chosen parameters point of view. It provided a number of data resulting from Atena programme while further data were obtained by subsequent calculations. The modelled panels were examined for their behaviour while three of their parameters, namely concrete strength, reinforcement cross-section area, and concrete covering, were changing. Behaviour of the panels was recorded in graphs.

As for concrete strength change, three panel groups were created, namely for strength $25 \mathrm{MPa}, 23 \mathrm{MPa}$ and $21 \mathrm{MPa}$. As the other parameters were changing, three sets of curves were obtained in each group.

As for reinforcement cross-section area change, in each group of panels a reinforcement bar diameter was different, namely $7 \mathrm{~mm}, 8 \mathrm{~mm}$, and $10 \mathrm{~mm}$. Accordingly, by changing the other parameters three sets of curves were obtained in each group.

As for changing concrete covering, its values were $10 \mathrm{~mm}, 20 \mathrm{~mm}$, and $30 \mathrm{~mm}$. Likewise, by changing the other parameters three sets of curves were obtained in each group.
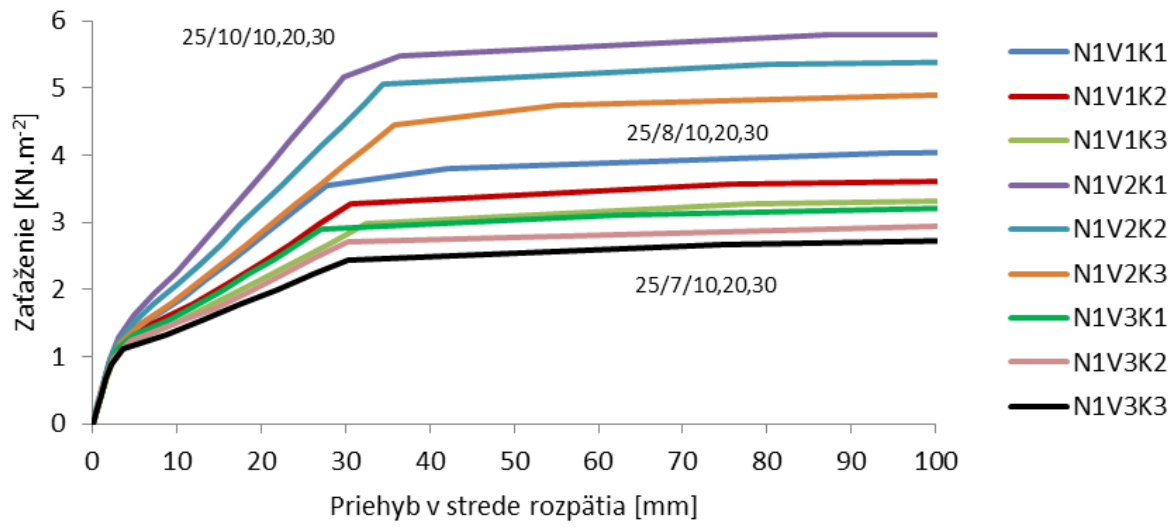

Fig. 7. Stress strain diagram - strength of concrete $25 \mathrm{MPa}-1$. Group. 


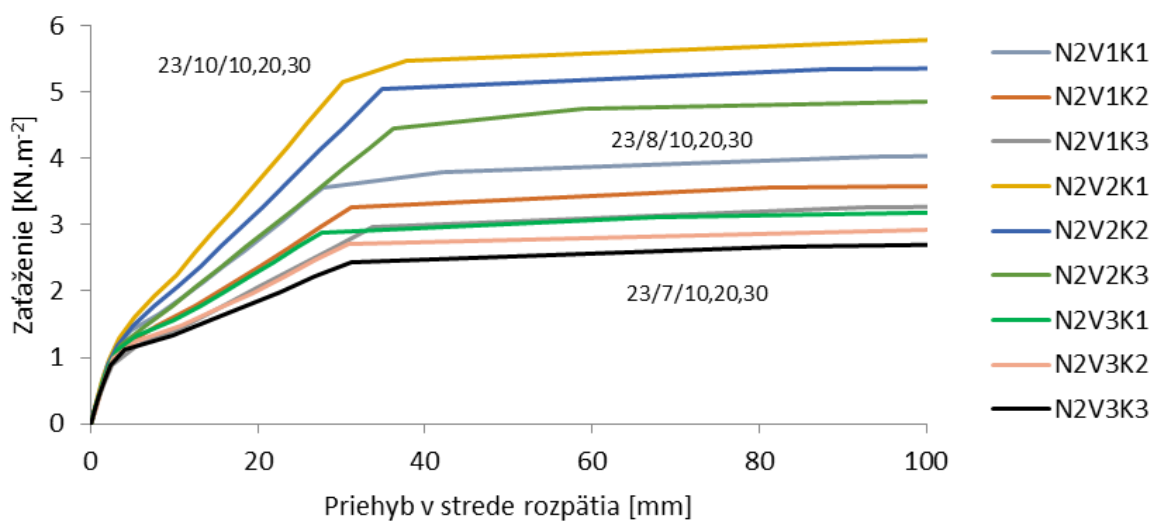

Fig. 8. Stress strain diagram - strength of concrete $23 \mathrm{MPa}-2$. Group.

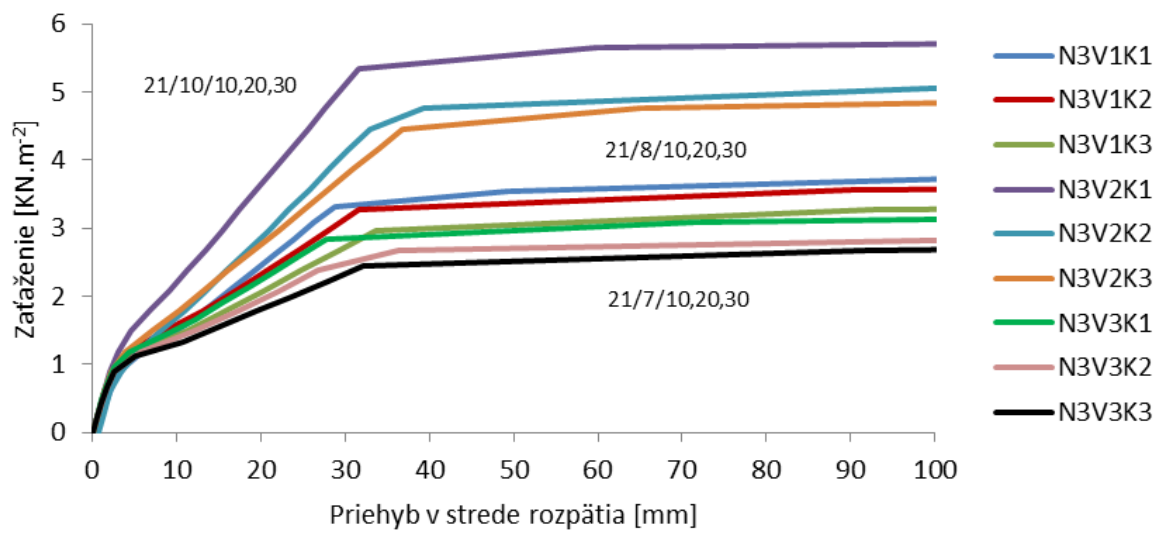

Fig. 9. Stress strain diagram - strength of concrete $21 \mathrm{MPa}-3$. Group.

Evaluation of individual graphs brought interesting results indicating how changes in chosen parameters can influence panel deflections in relation with loading. To make orientation in graphs easier, each set of curves in each group is labelled in the same form concrete strength / reinforcement diameter / concrete covering.

Fig.7, 8, 9 show a demonstrative compound graph presenting deflection-load ratios in beams with equal concrete strength $25 \mathrm{MPa}, 23 \mathrm{MPa}$ and $21 \mathrm{MPa}$. The graphs showed that based on panel deflection comparison, a change in concrete strength does not have a significant impact on resistance increase. The second parameter - reinforcement diameter is obviously more important. The presented graphs clearly show that in all three groups (for concrete strength $25 \mathrm{MPa}, 23 \mathrm{MPa}, 21 \mathrm{MPa}$ ) panels with reinforcement diameter $10 \mathrm{~mm}$ showed approximately identical deflection at higher load levels. Other beams with reinforcement diameters $8 \mathrm{~mm}$ and $7 \mathrm{~mm}$ showed identical deflection at lower load levels. The last parameter - concrete covering - has approximately identical impact within panel groups with the same strength and the same reinforcement diameter. The higher concrete covering, the lower resistance which is in connection with an arm of inner forces in the cross-section. 


\section{Conclusion}

The parametric study showed possible behaviour of ceiling panels while changing particular chosen parameters (concrete class, concrete covering and reinforcement diameter). Based on the modelled panels simulation (27 beams) and their behaviour presented by a load-deflection ratio, it may be concluded that a change in concrete strength does not significantly influence panel resistance, while a higher resistance was observed in models with the largest reinforcement diameter $(10 \mathrm{~mm})$. Concrete covering considerably influenced resistance only on condition of identical concrete strength, and at the same time, it was proved that the higher concrete covering is used, the lower resistance occurs. It can be stated that in the case of the modelled ceiling panels, concrete strength and concrete covering do not have a significant impact on resistance. The only parameter which could help increase resistance is the reinforcement diameter, in which case diameter $10 \mathrm{~mm}$ appears to be suitable. Last but not least knowledge is the discovery that in the case of the modelled beam when loaded until the limit deflection was reached, a crack width did not exceed a limit value.

It is appropriate to compare the parametric analysis results with the values measured on actual ceiling panels, to focus on possible proved result concordance, and to use this

This work was supported by the Scientific Grant Agency of the Ministry of Education of Slovak Republic and the Slovak Academy of Sciences under Project VEGA 1/0661/16.

\section{References}

1. I. Hegedüsová, S. Priganc, Property Analysis of Concrete Panels in an Aggressive Environment. Faculty of Civil Engineering, Technical University in Košice (2015)

2. ATENA Program Documentation Part 8, User's Manual for ATENA GiD Interface, (30.9.2013), http://www.cervenka.cz

3. ATENA Program Documentation Part 1, Theory, (14.3.2012), http://www.cervenka.cz

4. STN EN 1992-1-1 Eurocode 2: Design of concrete structures - Part 1-1: General reles and rules for buildings. 1

5. Š. Pogran, a kol., Quality of internal environment in stable buildings, Nitra (2011)

6. S. Priganc, I. Hegedüsová, Degradation degree of reinforced concrete ceiling panels in an agricultural building, Special concretes, Sekurkon Praha, (2009) 